\title{
Apuntes y documentos para la biografía de Rubén Darío
}

EPOCAS DE NIÑEZ Y ADOLESCENCIA.

Dadas las circunstancias en que Dario escribió, o, más exactamente; dictó, la historia de su vida, no es de extrañar que él incurriera en palpables errores y omisiones, y que, como gran soñador que fué, a veces confundiera en sus recuerdos la fantásía con el hecho; pues bien sabido es que esa su sabrosa autobiografía, aunque rica en limminosos detalles de sil vida y de su sér, no reprêsenta más que una serie de improvisaciones mediante matinales esfuerzos de memoria que hacia el poeta, aúin soñoliento, mientras se desayunaba reclinado en su lecho en un hotel de Buenos Aires. Con todos sus defectos, sin embargo, esos rasgos autobiográficos siguen siendo, y creemos que siempre serán por más que se insista en apocar su exactitud, la base más sólida y más completa para la biografía definitiva que aún queda por escribirse.

En verdad, el pecado mayor de la autobiografía es su brevedad. El ya rico caudal de datos que se ha acumulado en cuanto a la juventud y madurez de Dario, tiende a completar y precisar, más bien que a desvirtuar, las memorias del poeta. Caso 
idéntico ocurre con unos artículos que referentes a su niñez y adolescencia nos ha sido dado hallar en revistas $y$ diarios de antaño, $y$ que hoy reproducimos $y$ que, debido a su alto valor informativo, bien merecen ser rescatados de la obscuridad en que han quedado sepultados. (I) En cuanto atañe a estas épocas, hay que considerar, además, la obra del "poeta niño", que en si constituye una fuente nada despreciable de datos biográficos, pues mucho de lo que Dario remorara más o menós vagamente a la distancia de la nadurez, se halla aún tibio y palpitante en poemas de la sazón.

Uno de los artículos arriba aludidos es nada menos que de pluma de uno de los primeros maestros de Rubén, don Felipe Ibarra: (2) "Bien lo recuerdo -decía éste en 1907- Hace más de veinticinco años, una tarde de otoño pascaba yo con un colega mío por la Calle Real de la metrópoli nicaragüiense, y al pasar por las Cuatro Esquinas advertí que un niño, en la casa de doña Bernarda Sarmiento, primoreaba afanosamente en un acordeón. (3) Mi compañero y yo entramos en aquella casa, porque nos dió prurito de conocer al músico infantil. Era un muchacho endeble, cabezón, crenchas rubias, tez blanca, rostro aquilino, frente espaciosa, ojos grandes y centelleantes. Desde aquella tarde fuí su amigo; y como yo era profesor de primera enseñanza, su madre adoptiva, la señora Sarmiento, lo mandó a mi escuela. Por esta circunstancia pude comprender desde el principio, que en la cabeza de aquel humilde párvulo, se albergaba un intelecto monstruoso; pues en tan corta edad, y cuatndo apenas sabia leer y escribir, ya hacía muy buenos versos, que cmpezó a dar a luz, a veces ligeramente castigados por mi. (4) Era Rubén Darío.

"Bièn To recuerdo "Yo le enseñé el Cristus y el Catón cristiano, y el Catecismo del Padre Ripalda; porque en aquella época en nuestro país, eso era lo que de rigor se enseñaba a los chi- 
quitines de las escuelas elementales: Yo fuí quien escuché sus primeros trinos y gorjeos": (5)

Evidentemente, no se conoce la verdadera obra primigenia de Rubén, pues la composición más temprana que hasta nosotros ha llegado es el "In Memoriam" que apareció en las columnas de "El Termómetro", diciembre de 1878 , (6) y que es precisamente el poẹma con que nuestro bardo, según él mismo, efectuarà stl debut literario en la prensa nicaragüense. (7) Entonces estaba él en vísperas de cumplir sus doce años de edad. Entre las composiciones cuyas fechas pueden precisarse en fuentes dignas de confianza, a este "In Memoriam" siguen cronológicamente los versos de 1880 : (8) la cutita amorosa, el grito romántico, y los dulces cantares a la Naturaleza, que habían de dejar definitivamente establecido el prestigio del "poeta niño".

En r88I la fama de Rubén cruzaba ya las fronteras de Nicaragua con sutu "Oda a Víctor Hugo", la cual fué reprôducida en la revista salvadorense "La Juventud", con los siguientes comentarios de st distinguido redactor, don Ramón Mayorga Rivas:

"A más de un lector parecerá increíble que el autor de esta oda sea un niño que aún no ha cumplido quince años. Rubén Dario es la esperanza más ristueña del Parnaso nicaragitense, y a su edad, pocos, muy pocos en Centro América, han alcanzado un exito tan brillante en el cultivo de la gaya ciencia. Sus ensayos poéticos revelan el numen que le inspira, y reúne, a una inteligencia clara, tin sentimentalismo delicado. Mucho hemos vacilado al escribir estas líneas, porque al elogiarle hemos temido hacer un mal al tierno poeta; pero nos ha alentado la idea dc que no se detendrá en su camino a contemplar envanecido los primeros latureles que le arroja uno de sus compatriotas, $y$ que, por el contrario, cobrará nuevo brío para dedicarse al estudio, que es el único medio por el cual potrá en el porvenir hacerse verdaderamente digno de figurar en el catálogo de los poetas amerieanos. Stu "Oda a Victor Hugo". "La Naturaleza"'s su 
composición titulada "La ley escrita" y otras más, son el bello prólogo de una gloria literaria. Sería muy lamentable el que Rubén Dario defraudase las esperanzas de nuestra patria, Nicaragua, donde hoy se inicia una era próspera para las letras. Ojalá que comprenda cuál es el destino del poeta, apóstol del progreso e intérprete de los más elevados y sublimes sentimientos del corazón! Confiamos en su talento para que no vaya a engreírse con los aplausos que hoy le tributamos, como admiradores de las felices disposiciones para la poesía con que la Naturaleza le ha dotado. Rubén Darío debe procurar hacerse digno de Apolo; dedicándose a adquirir cuantos conocimientos pueda y sujetando los impetus de su. fantasía a las prescripciones del buen gusto, $y$ en cuanto le sea posible, a las reglas del arte. Si persevera en el comercio con las Musas con la dedicación que hasta ahora, no vacilamos en augurarle espléndidos triunfos en la poesía de mi patria, que se halla dignamente representada en Zamora, Díaz, Iribarren, Juárez, Aragón, Medina Salinas, Ibarra y otros vates. Mientras tanto no dudamos que aceptará las indicaciones que siempre le hemos hecho, y que ahora le repetimos con motivo de la publicación de su valiente Oda al gran poeta del siglo". (9)

Con esta "Oda a Víctor Hugo" se inicia una serie de composiciones que representan la primera empresa revolucionaria en que participara el futuro caudillo del movimiento modernista en las letras hispanas. Si para contar el cuento azul tuvo que pasar a Santiago de Chile, para cantar el modernismo político-social no necesitó moverse de León de Nicaragua. .

Siendo León el centro intelectual de la República, fué también la plaza fuerte nicaragüense del federo-liberalismo centroamericano. Caida la República Federal de Centroamérica, León había de convertirse en foco de conspiraciones contra el réginen del Partido Conservador, llegando a ser, años más tarde, cuna de pujantes rebeliones bajo el mando del célebre caudillo general Máximo Jerez, quien en 1869 logró formar un gobierno provisional con amplios poderes para derrocar a las autoridades existerites e implantar los principios enunciados en su progra- 
ma: Atención especial a la instrucción pública, liberalidad de la enseñanza, unidad en el continente americano para el sostén del progreso y de la libertad republicana, la restauración de la unión centroamericana aunque para esto fuera necesario apelar. a la fuerza de las armas, principios liberales en asuntos de religión en tanto cuanto fuese voluntariamente aceptado por las convicciones del pueblo, supresión de los monopolios, protección de la industria y del comercio, etc., etc. (ro)

Los padres adoptivos de Rubén,. el coronel Félix Ramírez y su esposa doña Bernarda, fueron amigos muy cercanos del general Jerez, pues éste fué nada menos que padrino de bautismo de nuestro poeta. (II) La tradición piadosa que reinaba en el hogar de los esposos Ramírez no impidió que aun doña Bernarda, cuya intransigencia en asuntos de religión consta en la autobiografía, simpatizara con la ideología del Partido Liberal, cuyas tendencias anticlericales de antaño habían tomado raíces profundas durante las riñas que finalmente aportaron la caída de la República Federal de Centroamérica. En cuanto al coronel Ramírez Dario le recordó como a "un militar bravo y patriota, de los unionistas de Centroamérica, con el famoso caudillo general Máximo Jerez". (12) Más adelante, refiriéndose a la vida cotidiana en casa de sus padres adoptivos, añade el poeta: "Por las noches había tertulia... Llegaban hombres de política, y se hablaba de revoluciones". (13)

A los catorce años de edad ( 1881 ), Rubén se hallaba ya en plena batalla político-social-religiosa cantando a la Unión Centroamericana en su lira templada ante el diapasón de Víctor Hugo, quien fué el único rival de Máximo Jerez en la ideología del "poeta niño". No deja de ser simbólico que en la ya mencionada oda al ilustre cantor del Momotombo, el rotundo cuanz to juvenil bardo nicaragüense fundicra en un mismo escudo los colores del liberalismo francés y centroamericano:

Salve genio inmortal! Salve profeta!

2. cuya voz sonora y prepotente 
tiemblan los opresores en sus tronos!

La libertad como radiosa llama

reverbera en tu mente,

y con su ardor tu corazón inflama!

"El Progreso sin fin", ése es tu lema

y la insignia que lleva tu bandera...

"El Progreso sin fin", ¿qué significa

tal palabra? Pues bien: es Jesucristo

predicando igualdad y unión al pueblo,

y muriendo en su cruz: es Galileo

ceñido de su fúlgida diadema

que exclama: $E$ PUR SI MUove, aun a despecho

del Fanatismo cruel...'(I4)

Los poemas de combate que escribiera Rubén en I88I cobran especial interés ante la luz de algunos acontecimientos ocurridos a la sazón. Los odios tradicionales entre el clero y el Partido Liberal llegaron una vez más al punto de la violencia a raíz de ciertas ideas promulgadas en la inauguración del Instituto de Occidente, de León. Algunos profesores, entre los cuales se hallaba el doctor José Léonard, mencionado por Darío en sus memorias, (I5) mantuvieron que las enseñanzas de Cristo constituían "la única base verdadera de la instrucción", y que la libertad de conciencia y de palabra era "indispensable para la enseñanza del hombre libre". (I6) A esto se levantó la voz de protesta de parte de los padres jesuítas que diez años antes habían llegado a León expulsados de Guatemala por el gobierno liberal de García Granados.

"Estos -escribe Bancroft-, en compañía de un tal Apolonio Orozco, acusaron a Leonard y a Calderón de librepensadores y de enemigos de la religión. Los cuarenta o cinctienta padres que residían en León tomaron medidas enérgicas en el asunto, y dos días más tarde apenas si quedaba persona en el lu* gar a quien no se le hubiera prevenido acerca del peligro que corría la religión de sus padres ante la propaganda de los librepensadores del Instituto. Contando con el apoyo de la chusma fanática, los jesuitas asumieron. una actitud atudaz y exigieron 
acción inmediata de parte del Obispo Ulloa y Larios. Este, sin embargo, se negó a apoyar su causa, lo cual los condujo a la exasperación. Mientras tanto, la gentuza se había amotinado. Grupos de hombres armados se atrincheraron en el viejo convento de la Recolección... El gobierno supremo tomó medidas inmediatas... y, una vez capturados los rebeldes, expulsó del país a los jesuítas. Se juzgó que el verdadero objeto de estos movimientos ( 17 ) era de derribar a Zavala y poner a Pedro Balladares en el sillón presidencial. Parece que se trataba, por un tiempo, de quién había de gobernar - el gobierno o los jesuítas. El asunto quedó decidido mediante la energía de $\mathrm{Za-}$ vala", (18)

El régimen estricta y literalmente "liberal-conservador" del Presidente Zavala, que tantos beneficios aportó al país, no se libró ni de los ataques de un extremo ni de los del otro. La parte que a los elementos radicales corresponde, puede verse en un pasaje de Darío que se refiere precisamęnte a esté año y que no deja de guardar relación con los acontecimientos arriba referidos:

"Se publicaba en León un periódico político titulado La Verdad. Se me llamó a la redacción - tenía a la sazón cerca de catorce años- se me hizo escribir articulos de combate que yo redactaba a la manera de un escritor ecuatoriano, famoso, violento, castizo e ilustre, llamado Juan Montalvo... Como el periódico La Verdad era de la oposición, mis estilados denuestos, iban contra el gobierno, y el gobierno se escamó. Se me acusaba como vago, y me libré de las oficiales iras porque un doctor pedagogo, liberal $y$ de buen querer, declaró que no podia ser vago quien como yo era profesor en el colegio que él dirigía. En efecto: desde hacía algún tiempo, enseñaba yo grámática en tal establecimiento". (19)

La alusión al caso de los jesuitas se hace evidente en dos estrofas del poema que Rubén leyera en la inauguración del Ateneo de León: 
Sí; la ignorancia maldita en forma de hidra se escapa, bajo asquerosa solapa a guerra y discordia incita; ladra, vocifera y grita y hace brotar del abismo al cuervo del Fanatismo que por su pico enlodado atroja crimen, pecado, y tremendo obscurantismo!

Mas, presto, presto se funden con el fuego de la Idea $y$ en oleada gigantea entre los abismos se hunden; luchan, braman, se confunden, se agitan en su elemento, y siempre, a cada momento, miran que les amenaza y que les quema y abrasa la llama del pensamiento! (20)

En la velada organizada por el Partido Liberal en homenaje al general Máximo Jerez con motivo de su muerte; diciembre de i881, cupo al poeta honrar la memoria del héroe de León en estrofas de dolor, ira y esperanza:

\author{
Jerez... deja que te vea! \\ Pensador agigantado, \\ semi-dios transfigurado \\ en el Tabor de tu idea! \\ Tu nombre, patrio amor crea; \\ porque tu nombre, Jerez, \\ infunde con altivez \\ en nuestra humilde pobreza, \\ fuegos del alma francesa; \\ rayos del Noventa y Tres. \\ Oh, tremendo sacrificio! \\ Oh, mundanal sufrimiento! \\ Para todo pensamiento, \\ hay eterno Santo Oficio. \\ Que se maldiga a Voltaire; \\ que se eleve a Torquemada,
}


y se conviertan en nada Razón, Luz, Ciencia, Saber. Que se destruya en su sér a la humana inteligencia; que caiga el arte, la ciencia; que el genio se enerve y muera, y que sea una quimera la libertad de conciencia.

Mas, silencio! ¿Quién se atreve a blasfemar así ahora, ante la luz redentora de este siglo diez y nueve? ¿No sentís que ya se mueve, que ya se incorpora el mundo, que su letargo profundo, hoy sacude? $Y$ en verdad; siembra de la libertad el árbol bello y profundo. .

Y tí, Jerez, duerme en tanto, en la tumba que os contiene, hasta que tierno resuene de la Unión el dulce canto; hasta que nos cubra cl manto de la aurora del mañana, que entonces nuestra alma ufana mientras el bronce retumba, cantará, allí, en vuestra tumba, LA UNIÓN CENTROAMERICANA. (2I)

En cuanto a su partida de León, que marca una larga y novelesca peregrinación que habia de durar hasta el último de sus días, encontramos en sus memorias un pasaje por demás pintoresco aunque no del todo preciso:

"Por este tiempo - dice el pocta, sin darnos una idea de la fecha a que se refiere-llegaron a León unos hombres politicos, senadores, diputados, que sabían de la fama del 'poeta niño'. Me conocieron. Me hicieron recitar versos. Me dijeron que era preciso que fuera a la capital. La mamá Bernarda me echó la bendición, y me partí para Managua...

"A la sazón estaba reunido el Congreso.

"Era presidente de él un anciano granadino, calvo, conser- 
vador, rico y religioso, llamado don Pedro Joaquín Chamorro. Yo estaba protegido por los miembros del Congreso que pertenecían al partido liberal, $y$ es claro que en mis poesías y versos ardía el más violento, desenfrenado y crudo liberalismo...

"Presentaron los diputados amigos una moción al Congreso para que yo fuese enviado a Europa a educarme por cuenta de la nación. El decreto, con algunas enmiendas, fué sometido a la aprobación del presidente. En esos días se dió una fiesta en el palacio presidencial, a la cual fuí invitado, como un número curioso, para alegrar con mis versos los oídos de los asistentes. Llego y, tras las músicas de la banda militar, se me pide que recite: Extraje de mi bolsillo una larga serie de décimas, todas ellas rojas de radicalismo antirreligioso, detonantes, posiblemente ateas, y que causaron un efecto de los diablos. Al concluir, entre escasos aplausos de mis amigos, oí los murmullos de los graves senadores, y vi moverse desoladamente la cabeza del presidente Chamorro. (22) Este me llamó y, poniéndome la mano en un hombro, me dijo, más o menos:- -Hijo mio, si así escribes ahora contra la religión de tus padres y de tu patria, ¿qué será si te vas a Europa a aprender cosas peores?". Y así la disposición del Congreso no fué cumplida". (23)

- Afortunadamente, tales datos como là fecha en que ocurrió esțe curioso incidente, y el nombre de la composición recitada por el poeta en dicha ocasión, así como también algunos otros detalles de eminente valor biográfico, constan en un luminoso editorial de "El Ferrocarril" de Managua, de febrero de 1882:

'Bastante conocido es ya el nombre del 'Poeta niño'. Muchos saben que, apenas un adolescente, sin mayor educación que la intuición del genio, ha hecho buenos versos y cantado a la Razón, a la Libertad y a todo aquello que eleva el alma y engrandece el pensamiento. Pero lo que muchos ignoran, lo que pocos saben es que Darío, tan mimado por las musas, tan rico en inteligencia, ha sido muy desfavorecido por la caprichosa fortuna; es absolutamente pobre... (24)

"Hoy se encuentra en la capital y viene a solicitar la protección de la nación para ir a continuar su carrera debidamente 
en el exterior. Ojalá obtenga un buen éxito! Como nicaragüenses amantes de las glorias patrias, como jóvenes entusiastas por el talento y por el verdadero mérito, deseamos ansiosamente que el Soberano Congreso y el Supremo Gobierno secunden y apoyen sus nobles propósitos. De ese niño puede restiltar un gran poeta, que al par de darle nombre y gloria a Nicaragua revele el porvenir a las generaciones futuras operando una revolución en la literatura universal. Víctor Hugo lo ha dicho, 'todo poeta que empieza es considerado como una cosa sagrada.- ¿ ¿Sabéis si ese pobre estudiante a quien codeáis no llegará algún día a ser un Schiller? A nuestro modo de ver, todo colegial que hace círculos o tira líneas en la pared, tal vez sea un Pascal; todo niño que bosqueja un perfil en la arena, podrá llegar a ser un Giorno'.

"Y por el contrario, opinamos que cuando al talento no se le educa convenientemente, contrariando sus disposiciones, puede ser una amenaza para la sociedad. Observando un río, cuando se le impide su curso natural, destruye los campos y produce cataclismos. El talento no es otra cosa que una corriente de ideas, un río de pensamientos.

"Nosotros no conocíamos a Darío; habíamos leído sus producciones y habían dejado en nuestro espíritu algo como la estela dé un barco que riela sobre ondas espumosas, algo como el luminar del rayo que rasga el espacio, pero ahora que le hemos visto, que hemos oído sus suaves armonías, se ha despertado en nuestra alma toda la simpatía, todo el vivo interés que inspira la virtud, el talento y la desgracia a la vez. Le ofrecemos un corazón fraternal.

"En la noche de la instalación del Congreso leyó a presencia de los Representantes un bellísimo poema, 'El Libro', que dedicó al señor Presidente Zavala. Esa composición tiene valientes pensamientos, robusta entonación y dulce riqueza poética. Ai escuchar, creímos oír la musa ardiente de Plácido, la arrebatadora inspiración de Heredia y la dulce armonía de Palma". (25)

Esta extensa composición - consta de cien décimas- es, en verdad, la culminación de las ideas bosquejadas en los poemas 
de combate del año anterior. Su plan general, además, es el mismo que el de éstos, en el cual resalta la mezcla de estrofas de poesía pura, casi invariablemente dedicadas a la Naturale$\mathrm{za}$, con otras de carácter más o menos tendencioso. La novedad en este poema, comparándolo con los anteriores, yace principalmente en el concepto del Libro como símbolo de la Luz, la Belleza y el Amor; una nueva trinidad, podría decirse, contenida en Dios.

El Libro se compone de libros, a manera de tomos de la obra suprema. Tales son el hombre, en quien el Creador puso "el incendio de la idea"; la Naturaleza; y el libro de la vida, inspirado por "la bella musà hebrea". Este último:

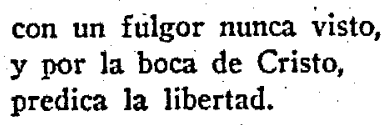

Como en la composición titulada "El Ateneo de León", en este poema entra una larga procesión de las grandes celebridades de todos los tiempos. Homero, Cicerón, Virgilio, Dante, Galileo, Cervantes, Shakespeare, Voltaire, Hugo, etc., etc., desfilan tras de Cristo como páginas gloriosas del Libro del Señor. Esta procesión desde luego, no carece de estrofas en que centellean los colores del Partido Liberal. Así, el Libro:

$$
\begin{aligned}
& \text { Ya nos brinda con Renán } \\
& \text { una vida de Jesús; } \\
& \text { ya nos envuelve en su luz } \\
& \text { la palabra de Laurent; } \\
& \text { ya enseña con Palletan } \\
& \text { mil torrentes de verdad. } \\
& \text { Ya predica la igualdad, } \\
& \text { y odio al autócrata, al Rey, } \\
& \text { con las tablas de la ley } \\
& \text { de la nueva libertad. }
\end{aligned}
$$

Hacia fines de la composición, el poeta entra de lleno en la materia blandiendo su pluma candente contra los enemigos 
que el Libro tiene sobre la faz de la Tierra. Frente a Bacon, Darwin, Malebranche, Lutero, Chateaubriand, Spinoza, que vierten armonía, luz y belleza, están Maratón, Atila, Segismundo, César, Napoleón, cuyas glorias son de "humo, sangre y ceniza". Las estrofas más furibundas, sin embargo, son las referentes al Vaticano: :

\author{
Lugar do, con rudo acento \\ y por voluntad suprema, \\ el libro... el libro se quema \\ $y$ se mata el pensamiento; \\ lugar do con ardimiento \\ se predica la orfándad, \\ do es nada la caridad, \\ do farsas $y$ tradiciones \\ fulminan excomuniones \\ a la santa Libertad. \\ Maldicen al libro, sí,. \\ con un criminal deseo... \\ ¿Dónde estuvo Galileo \\ para retractarse? Allí!... \\ Cristo, Cristo!... Ya de ti \\ se burla esta gente extraña, \\ su corazón vierte saña, \\ venden reliquias y bulas, \\ y ya las frases son nulas \\ del Sermón de la Montaña.
}

No sin ciertas reservas, desde luego, ha de tomarse el radical anticlericalismo que campea en estas composiciones. En efecto, poco antes de partir para Managua, el poeta, angustiado por el "terror católico" que desde su niñez llevaba impreso en lo más íntimo de su sér, se había visto forzado a interrumpir sus actividades relacionadas con el Partido Liberal. "Brotó en mí el amor triunfante - dice Darío refiriéndose a tal época- y fuí un muchacho con ojeras, con sueños y que se iba a confesar todos los sábados". (26) Que su actitud crítica para con el clero no fué cosa del momento, sin embargo, consta en un sinnúmero de alusiones fugitivas a través de toda su obra, $\mathrm{y}$, específicamente, en su composición titulada "Pro Domo Mea", 
I89r, escrita en defensa de la Mercurial Eclesiástica de Juan Montalvo contra los ataques de "La Unión Católica". (27) En cuanto se refiere a la unión centroamericana, los esfuerzos de Darío tampoco se limitaron a sus primeros arranques juveniles. La campaña que en pro de tal ideal emprendiera ocho años más tarde en El Salvador, bajo los auspicios del Presidente Menéndez, es ya conocida por la misma obra del poeta, (28) como. también por lo que a este respecto se ha escrito. (29) Añadamos, en conclusión, que en tales obras de madurez como España contemporánea, El viaje a Nicaragua, Prosa politica, etc., y en poemas como "Salutación del optimista", "Letanía de Nuestro Señor Don Quijote", “A Colón”, "A Roosevelt", y en muchas otras composiciones en prosa y en verso, consta que tanto su lealtad a los principios liberales de progreso, justicia y libertad, como su vivo interés en los destinos de su pueblo, en el sentido más vasto de esta última palabra, habían de persistir a través de las paradójicas tendencias de su alma compleja.

\section{ANTonio M. DE LA ToRre, Universidad de Oklahoma.}

(1) - -De entre los documentos que conocemos con respecto a la niñez y adolescencia del poeta, tres figuran ya en la bịbliografía rubendariana, por cuya razón no los incluímos aquí. Tales son: "La casa materna de Rubén Datio en Nicaragua", por Ramón Avilés, en "El Nuevo Tiempo", Tegucigalpa, 19r4; "La Escuela de Doña Jacoba", del mismo autor, en "Germinal", Tegucigalpa, I, (18), 1916; y "Rubén Darío tradicional", por Anselmo Fletes Bolaños, en "Tegucigalpa", Tegucigalpa, 1918. Este último ha sido reproducido, del "Diario de Granada", noviembre 24, 1907, en la obra del Dr. Arturo Torres-Rioseco, Rubén Dario, Harvard University Press, 1931. Idéntica versión apareciỏ también en "Athenea", Número Especial, San José de Costa Rica, novientbre de 1917.

(2).-En pág. I5 de la Autobiografía, Ed. Maucci, se lee: "Se me hacia ir a una escuela pública. Aún vive el buen maestro..., el licenciado Felipe Ibarra... Alli se enseñaba la cartilla, el Catón cristiano..." etc. Estas últimas palabras parecen indicar que el poeta conscientemente confirma los datos hallados en el artículo de don Felipe Ibarra, escrito cinco años antes que la autobiografia (1912).

(3).-Refiriéndose a su niniez, Darío escribió: "En casa de Debayle, a 
poco tiempo de nucstra primera intimidad, bajo la complacencia maternal, fraternizábamos furiosamente en el acordeón". Véase Rubén Darío, Todo al vnelo, p. Ior. Habría sido de extrañar que Darío no hubiera tratado de dar expresión a su sensibilidad artística en la ejecución de algún instrumento musical. Tambiěn el señor Alberto Tena cuenta que el poeta, hallándose en París, por el año I9O3, tocaba en el piano canciones de su tierra. Véase Rubén Dario, Ramillete de reflexiones, p. 207.

(4).-En la Autobiografia, p. 20, se lee: "Yo nunca aprendí a hacer versos, ello fué en mi orgánico, natural, nacido".

(5).- "El Fénix de los Poetas", reproducido con un corto comentario en Capitulos que se le olvidaron a Rubén Dario, Sección III, "El niño que tocaba el acordeón", de Juan Ramón Avilés, que conocemos mediante una copia a máquina existente en la biblioteca del poeta Rafael Heliodoro Valle, México, D. F. Dichos Capitulos etc., del señor Avilés, evidentemente aparecieron en diarios o revistas de escasa circulación, pues el único que figura en la bibliografía rubendariana es el que lleva por subtítulo "Los apuros que le hizo pasar la teosofía", referente a la madurez del poeta, y publicado en "El Universal Ilustrado", México, 1923, VI (305).

(6).-Rubén Dario, Poemas de adolescencia, p. 18. Véase también la Autobiografia, p. 32.

(7).-Autobiografía, p. 32. Darío se equivoca por un año, sin embargo, en cuanto a la fecha de la publicación de estos versos, pues dice que él estaba entonces por cumplir sus trece años de edad (1879).

(8).-A.-"El desengaño", "El poeta", "A..." (A Mercedes Maning), "La Naturaleza", publicados en diversos números de "EI Ensayo", Nicaragua, I880, y luego reproducidos por Ventura García Calderón ("Los primeros versos de Rubén Darío" en "Revue Hispanique", t. XL, 1918). La fecha de 1889 que en tal edición aparece al pie del poema titulado "La Naturaleza", se debe indudablemente a un error de imprenta. Esta misma composición va mencionada por don Ramón Mayorga Rivas en un artículo de I88I que citamòs en seguida. B.-En "La Noticia", Managua, febrero I4, 1916, apareció un artículo de Juan Ramón Avilés, "Apoteosis de Dario", en el cual se reproduce un poemita bajo el título de "A ti", fechado en diciembre 1880, que es parte de la composición que en el primer volumen de las Obras Completas (Poemas de adolescencia) figura con el nombre de "Tá y yo", sin fecha.

Es de suponer que sean contemporáneos a éstos, o aun anteriores, unos poemitas de álbum que, por estar todos cortados con el mismo patrón, sugieren una fórmula especial que desarrollara el poeta para sus versos de impromptu. En todos ellos, el galante bardo comienza con el elogio ya sea de una flor, de la aurora, del firmamento, o de algo similar, pero siempre acerca de la Naturaleza, y luègo compara aquello con la niña a quien los versos van dedicados. A este grupo pertenecen a "Merceditas García", "A la señorita Josefa Dubón", y "En el álbum de Sara"; a los cuales podrían añadirse dos más: "Romance" y "A unos ojos azules", que, aunque más extensos que los anteriores, obedecen al mismo plan general. ¿Son éstos tal 
vez los versos con que el "pocta niño" se captara la admiración de las damitas en esas fiestas domingueras en León, de que Darío nos habla en su Autobiografia? (Véase p. 23 de dicha obra). Desafortunadamente, pocos son los detalles precisos que se dan en las Obras Completas, y aun el dato "I878-1881" que aparece al final del primer volumen, Poemas de adolescencia, no es de fiarse por cuanto que en él figuran por lo menos siete composiciones que pertenecen a épocas posteriores: la "Serenata a Mercedes de Zavala", 1882, reproducida de "El Ferrocarril" de Managua, de dicho año, en "La Noticia", Managua, febrero 9, 1916; la "Serenata a Herminia Cha-. morro", mayo 16, 1886, reproducida en el mismo diario, febrero 10, 1916; "Los rizos de mi morena", agosto 4, 1884, reproducido en el mismo diario, febrero 13, I9r6; "A Sara Neuhaus de Ledgaid", 1899, véase Regino Boti, Para "Hipsipilas", pp. 9 y to; "El cantar de los cantares", 1883, idem, p. 9; "Del trópico", 1889, véase G. Alemán Bolaños, La juventud de Rubén Darío, p. 142; y "Canción de la noche en el mar", fechada en el "Océano Atlántico, MCMVI", como se ve al pie de la firma del poeta en el autógrafo que aparece en Rubén Darío, Poemas escogidos, prólogo de Leopoldo Lugones, "Lectura Selecta", No 4, México, 1916.

(9).-Reproducido en "Vida intelectual", San Salvador, junio de I907.

(to).-Hubert H. Bancroft, West American History, Vol. VIII, p. 472.

(ii).-Autobiografia, p. 9.

(I2).-Ibidem, p. 8.

(13).-Thidem, p. I2.

(14).- "Oda a Victor Hugo". La versión reproducida de "La Juventud", 188I, en "Vida intelectual" (véase nota 9) es más completa que la que aparece en Rubén Darío, Poemas de adolescencia, ofreciendo también algunas variantes.

(I5).-En p. 45 de la Autobiografía se lee: "En Managua conoci... al doctor José Leonard y Barthelot, que fué después mi profesor en el Instituto Leonés de Occidente..." El hecho es que Dario ya habia conocido al doctor Leonard en León, pues éste se hallaba en dicha ciudad en 1881, tn año antes de que Darío pasara a Managua. Véase cita correspondiente a la nota 25 .

(I6).-Bancroft, o. c., nota 54 p. 48.4 .

(17).- "Movimientos", en plural, puesto que Bancroft se reficre también al levantamiento que los jesuítas habian fomentado en Matagalpa a principios del mismo año, 188I. Véase nuestra nota 18.

(18).-Bancroft, o. c., pip. 484-5.

(19).-Autobiografia, p. $4 \mathrm{I}$.

(20).- "El Ateneo de León", en Rubén Darío, Pocmas de adolesccncia.

(21).--"Máximo Jerez", Ibidem.

(22) - No, desde luego, presidente de la República, como han creido cuantos de este incidente han tratado anteriormente, sin darse cuenta, por lo visto, de que cuando don Pedro Joaquín Chamorro terminó su periodo presidencial, 1879, Darío contaba sólo doce años de edad y aún no había salido de Lcón. El incidente que narra el poeta ocurrió en 1882 (véase cita 
correspondiente a la nota 25), siendo presidente de la República don Joaquín Zavala. Al principio de la presente cita, Darío dice que Chamorro era presidente del Congreso.

(23).-Autobiografía, pp. 43-5.

(24).- Omitimos una cita de unos versos de Zorrilla que en nada contribuyen a lo que se refiere a Darío.

(25).-Reproducido en "La Noticia", Managua, febrero 9, 1916.

(26).-Autobiografía, p. 43 .

(27).-Rubén Dario en Costa Rica, Ediciones Sarmiento, Cuadernos $15 \mathrm{y} I 6$, p. 88 .

(28).-Rubén Darío, Crónica politica.

(29).-G. Alemán Bolaños, La juventud de Rubch Dario. Contienc varios escritos de compañeros del poeta. 
